\title{
Increased Risk of Psychopathological Abnormalities in Subjects With Unilateral Hearing Loss: A Cross-Sectional Study
}

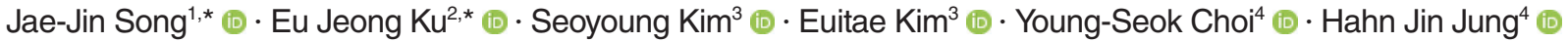 \\ ${ }^{1}$ Department of Otorhinolaryngology-Head and Neck Surgery, Seoul National University Bundang Hospital, Seongnam; ${ }^{2}$ Department of Internal \\ Medicine, Chungbuk National University Hospital, Chungbuk National University College of Medicine, Cheongju; ${ }^{3}$ Department of Psychiatry, \\ Seoul National University Bundang Hospital, Seongnam; ${ }^{4}$ Department of Otorhinolaryngology-Head and Neck Surgery, Chungbuk National \\ University Hospital, Chungbuk National University College of Medicine, Cheongju, Korea
}

Objectives. Although unilateral hearing loss (UHL) has been proven to be associated with educational and behavioral problems, few studies have investigated psychopathological abnormalities in this population. The aim of this study was to evaluate the psychopathological influence of UHL among Korean 19-year-old males.

Methods. The authors retrospectively compared the objective personality test profiles of 602 subjects with UHL with those of 23,790 peers with normal hearing. All participants in the current study were 19-year-old males who underwent a physical examination and completed the Korean Military Multiphasic Personality Inventory for conscription at the Military Manpower Administration from February 2015 to December 2016.

Results. Significantly higher scores were found on neurosis scales in the UHL group than in the normal-hearing group (50.9 \pm 10.8 vs. $44.9 \pm 6.0$ for anxiety; $51.0 \pm 10.5$ vs. $44.9 \pm 5.2$ for depression; $51.1 \pm 10.4$ vs. $45.1 \pm 6.81$ for somatization, all $P<0.001$ ). The psychopathy scales were also significantly higher in the UHL group than in the normal-hearing group ( $49.3 \pm 9.4$ vs. $46.3 \pm 5.7$ for schizophrenia; $51.1 \pm 11.2$ vs. $44.3 \pm 5.8$ for personality disorders; $51.1 \pm 10.5$ vs. $45.7 \pm 3.7$ for paranoia, all $P<0.001)$.

Conclusion. Nineteen-year-old males with UHL tended to have more abnormal results on personality tests than controls with normal hearing, suggesting that UHL may be related with a higher risk of psychopathology.

Keywords. Hearing Loss; Psychological Comorbidity; Depression, Anxiety; Unilateral Hearing Loss

\section{INTRODUCTION}

Unilateral hearing loss (UHL), which refers to the coexistence of a hearing impairment in one ear with normal hearing in the other, affects $0.5-1$ per 1,000 newborns [1,2]. Due to delayed-onset

\footnotetext{
- Received February 28, 2020

Revised May 15, 2020

Accepted June 10, 2020

- Corresponding author: Hahn Jin Jung

Department of Otorhinolaryngology-Head and Neck Surgery, Chungbuk

National University Hospital, 776 1(il)sunhwan-ro, Heungdeok-gu,

Cheongju 28644, Korea

Tel: +82-43-550-3933, Fax: +82-43-556-1090

E-mail: hahnjin2@naver.com

*The first two authors contributed equally to this study.
}

congenital UHL and acquired UHL, the prevalence increases to $3 \%-6 \%$ at school age, and $7.9 \%$ of U.S. adults are reported to have UHL $[3,4]$. Temporal bone anomalies such as an enlarged vestibular aqueduct and cochlear nerve deficiency are found in $28.9 \%-50 \%$ of UHL patients, and other etiologies including congenital cytomegalovirus infections, meningitis, and trauma may be associated with UHL [5-8].

In the past, UHL was thought to be a disease entity of negligible importance because subjects with UHL were thought to experience few, if any, communication or educational problems. However, since the 1980s, several studies have shown that UHL is associated with a higher rate of educational and behavioral problems, which may require repeating grades or additional educational assistance $[9,10]$. Studies have also demonstrated that school-

Copyright (C) 2021 by Korean Society of Otorhinolaryngology-Head and Neck Surgery.

This is an open-access article distributed under the terms of the Creative Commons Attribution Non-Commercial License (https://creativecommons.org/licenses/by-nc/4.0)

which permits unrestricted non-commercial use, distribution, and reproduction in any medium, provided the original work is properly cited. 
aged children with UHL have a higher risk of delays in speech and language development than their peers with normal hearing $[11,12]$. Moreover, behavioral and functional imaging studies have indicated that UHL may have negative effects on cognition and executive function $[13,14]$. In this regard, the importance of UHL in terms of speech-language development, academic performance, and cognitive function has now been widely accepted.

Despite this recognition, the impact of UHL on quality of life and, more specifically, on psychopathological abnormalities has not been thoroughly studied. Using quality-of-life-related questionnaires or hearing handicap inventories, a few recent studies have suggested that UHL may be associated with emotional and social-situational problems $[15,16]$. However, the psychopathological impact of UHL is poorly understood, since studies with a large number of subjects using standardized psychometric tests of personality and psychopathology such as the Minnesota Multiphasic Personality Inventory (MMPI) are scarce.

Previous studies have reported that bilateral hearing-impaired children are extremely vulnerable to poor psychosocial development and have higher levels of psychological distress than their normal-hearing peers $[17,18]$. Similarly, we hypothesized that UHL could also pose a risk of psychopathological problems, and this paper reports a retrospective cross-sectional study that was conducted to evaluate whether this hypothesis is true.

\section{MATERIALS AND METHODS}

\section{Subjects}

The current study is a retrospective cross-sectional study of 24,392 subjects; 602 suffering from severe or profound UHL ( $>70 \mathrm{~dB}$ on the affected side) and 23,790 normal hearing controls ( $<20 \mathrm{~dB}$ hearing loss). All participants in the current study were 19-year-old males who underwent physical examination for conscription at the Military Manpower Administration (MMA) from February 2015 to December 2016. In Korea, before joining the mandatory military service, all subjects underwent physical and psychological status evaluations by specialists from all departments of the MMA. The psychological status of the subjects was evaluated by the Korean Military Multiphasic Personality Inventory (KMPI) during the routine examination [19-24].

\section{H I G H L L I G G H T S}

- Few studies have investigated psychopathological abnormalities in individuals with unilateral hearing loss.

- Nineteen-year-old males with unilateral hearing loss tended to have more abnormal results on personality tests than controls with normal hearing.

- Unilateral hearing loss may be related to a higher risk of psychopathology.
All normal hearing subjects were interviewed by one physician and did not have any remarkable past medical history. The hearing thresholds of the UHL subjects $(n=602)$ were determined by pure tone audiometry (PTA) and auditory brainstem response, and they all showed normal air conduction thresholds on the contralateral ear ( $<20 \mathrm{~dB}$ hearing loss). The degree of UHL was evaluated by recent (within 3 months) PTA average. PTA average was defined as the average hearing threshold at 500, 1,000, 2,000, and 4,000 Hz. All UHL subjects included in the current study had severe or profound UHL. Participants who had been previously diagnosed with any psychiatric disorders such as depression, anxiety disorder, or schizophrenia were excluded from the study. Also, to maintain the homogeneity of the study group, subjects with unilateral conductive hearing loss or a history of previous temporal bone trauma or otologic surgical intervention were excluded.

The study was conducted in accordance with the Declaration of Helsinki and was approved by the Institutional Review Board of the Clinical Research Institute at Chungbuk National University Hospital (IRB No. 2019-01-008). Considering a retrospective review study design, written informed consent was waived.

\section{Korean Military Multiphasic Personality Inventory}

The KMPI has been developed for use in Korean conscription and has the same scoring system in psychological evaluation as the MMPI [19-24]. As an objective psychological evaluation of conscription, KMPI is used to distinguish between psychologically healthy and unhealthy subjects, as well as to provide early screening for psychiatric disorders and criminal behavior [25].

The KMPI is composed of subscales such as the validity scales (faking-good, faking-bad, and infrequency), neurosis scales (anxiety, depression, and somatization), psychopathy scales (schizophrenia, personality disorder, and paranoia), and specific content scales (criminal and military-related scales). The KMPI produces scores for each scale, which are transformed into a standardized T-score [22].Therefore, by comparing theT-scores of given groups, trends with regard to personality and psychopathology can be objectively analyzed same as in the MMPI. In this study, we evaluated the association between UHL and neurosis scale (anxiety, depression, and somatization), and psychopathy scale (schizophrenia, personality disorder, and paranoia).

\section{Statistical analysis}

Evaluation of the statistical significance of differences between groups was carried out using Student $t$-test. Statistical significance was set at $P<0.05$. The statistical comparisons were performed using IBM SPSS ver. 20.0 (IBM Corp., Armonk, NY, USA).

\section{RESULTS}

All 24,392 participants were 19-year-old Korean males without 
Table 1. Baseline demographic data of the study participants

\begin{tabular}{lccc}
\hline Variable & $\begin{array}{c}\text { Unilateral hearing } \\
\text { loss group }(\mathrm{n}=602)\end{array}$ & $\begin{array}{c}\text { Normal-hearing } \\
\text { group }(\mathrm{n}=23,790)\end{array}$ & P-value \\
\hline Height $(\mathrm{cm})$ & $173.0 \pm 5.8$ & $173.7 \pm 5.5$ & 0.271 \\
Weight $(\mathrm{kg})$ & $66.8 \pm 10.6$ & $67.1 \pm 5.9$ & 0.539 \\
BMI $\left(\mathrm{kg} / \mathrm{m}^{2}\right)$ & $22.3 \pm 3.1$ & $22.2 \pm 1.4$ & 0.405 \\
Systolic BP $(\mathrm{mmHg})$ & $122.8 \pm 12.8$ & $122.2 \pm 10.5$ & 0.234 \\
Diastolic BP $(\mathrm{mmHg})$ & $71.9 \pm 8.6$ & $70.5 \pm 7.8$ & 0.389 \\
\hline
\end{tabular}

Values are presented as mean \pm standard deviation.

$\mathrm{BMI}$, body mass index; BP, blood pressure.

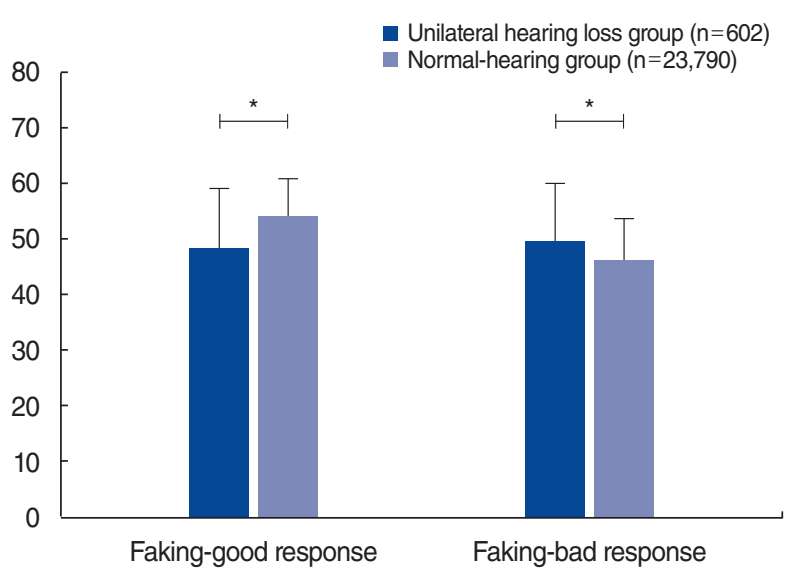

Fig. 1. Validity scales. ${ }^{*} P<0.001$.

a history of previous psychiatric problems. Significant differences in baseline characteristics were not found between the UHL and normal-hearing groups. Table 1 summarizes the detailed baseline demographic data of the participants.

The results of the KMPI in the UHL group significantly differed from those in the normal-hearing group. In the validity scales, the UHL group showed a significantly lower faking-good response than that of the normal hearing group ( $48.3 \pm 10.7$ vs. $54.1 \pm 6.8$, $P<0.001$ ), and the faking-bad response of the UHL group was significantly higher than that of the normal-hearing group (49.6 \pm 10.3 vs. $46.0 \pm 7.6, P<0.001$ ) (Fig. 1). In the neurosis scales, all three subscales (anxiety, depression, and somatization) had markedly higher scores in the UHL group than in the normal hearing group $(50.9 \pm 10.8$ vs. $44.9 \pm 6.0$ for the anxiety subscale; $51.0 \pm$ 10.5 vs. $44.9 \pm 5.2$ for the depression subscale; $51.1 \pm 10.4$ vs. $45.1 \pm 6.81$ for the somatization subscale, all $P<0.001$ ) (Fig. 2). Likewise, in the psychopathy scales, all three subscales (schizophrenia, personality disorder, and paranoia) had significantly higher scores in the UHL group ( $49.3 \pm 9.4$ vs. $46.3 \pm 5.7$ for the schizophrenia subscale; $51.1 \pm 11.2$ vs. $44.3 \pm 5.8$ for the personality disorder subscale; $51.1 \pm 10.5$ vs. $45.7 \pm 3.7$ for the paranoia subscale, all $P<0.001$ ) (Fig. 3).

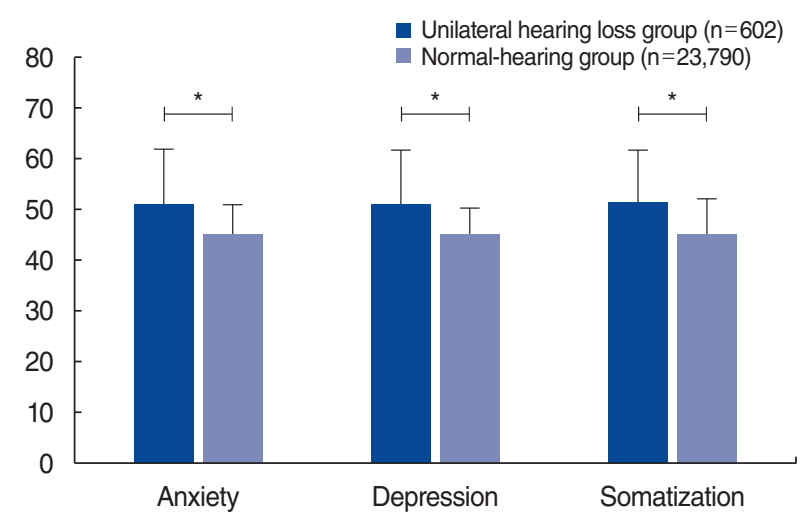

Fig. 2. Neurosis scales. ${ }^{*} P<0.001$.

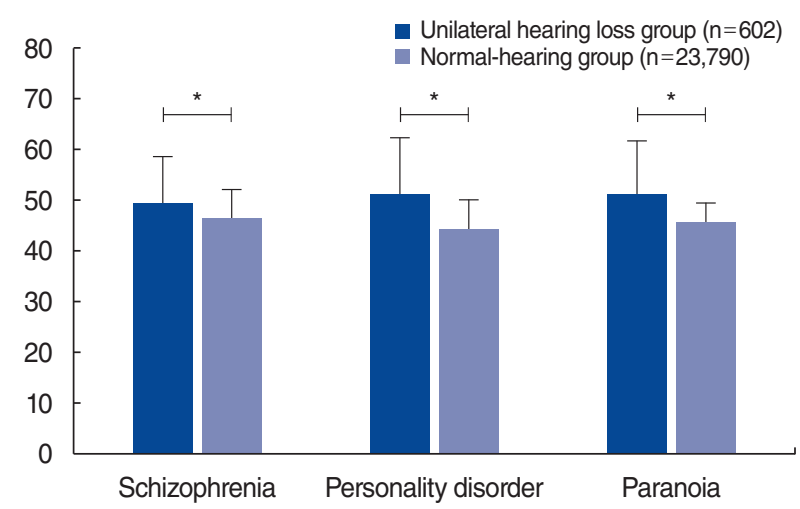

Fig. 3. Psychopathy scales. ${ }^{*} P<0.001$.

\section{DISCUSSION}

UHL is a relatively common disease. Single-sided deafness, the most extreme form of UHL, has been reported to have a prevalence between $0.1 \%$ to $3.0 \%$ in the pediatric population [26]. However, despite its relatively high prevalence, UHL has been under-recognized as a problem and thus not properly managed in children and young adolescents [27]. Rather, UHL has been regarded as "a happy feature of a misfortune" because affected children show generally normal development [6]. The treatment options for UHL range from no intervention to FM amplification systems, conventional hearing aids, hearing aids with contralateral routing of signals, bone-anchored hearing aids, and cochlear implantation [28-31]. However, in real-world clinical situations, the majority of young people with UHL only receive preferential seating at the front of the class and are educated on the importance of protecting the contralateral ear with normal hearing.

Many studies have explored correlations between mental health disorders and bilateral hearing impairment in pediatric and young adolescent populations [32]. Most of these studies reported that hearing-impaired children exhibited poorer psychological and quality-of-life outcomes than their normal-hearing peers [33]. Fellinger et al. [32] reported that the lifetime rate of depression 
among children with bilateral hearing impairment was $26.3 \%$, compared to $3.4 \%$ in their normal-hearing peers. However, not many studies have examined UHL. Since the 1970s, several investigators have demonstrated that children with UHL make more errors on sound localization tests due to the interaural time and intensity disparities [26,34]. Other reports indicated that adults with early-onset UHL showed problems in psychoacoustic performance such as sound localization and speech recognition in noisy environments [35-37]. However, to our knowledge, no studies have investigated the relationships between psychological problems and UHL. The authors hypothesized that UHL may be associated with psychological problems similar to those seen in bilateral hearing loss, and the results of the current study indicated that the UHL group showed a higher risk of neuropsychiatric disorders on various KMPI scales than the normal-hearing group.

In this study, we used three scales of the KMPI. First, the validity scales are composed of faking-bad response and fakinggood response. The reasons for faking bad can include making a "plea for help" and having a catastrophizing style, while the reasons for faking good include seeking to deny problems and desiring to appear psychologically healthy [38]. In the current study, the UHL group showed significantly higher faking-bad responses and lower faking-good responses than the normal-hearing group. In other words, the participants with UHL tended to exaggerate their symptoms more than their counterparts with normal hearing. Second, the neurosis scales are composed of anxiety, depression, and somatization subscales, which reveal the respondent's tendency toward these neurotic statuses. Third, the psychopathy scales comprise the schizophrenia, personality disorder, and paranoia subscales, which also address the status of social relations. In this study, the UHL group showed statistically significantly higher scores on the neurosis and psychopathy scales than the normal-hearing group. These findings suggest that UHL may significantly impact the psychological state of affected individuals.

Based on the results of the current study because many children are at a higher risk of psychological problems related to their UHL, it appears necessary for us to begin to reassess our general approach to this population. The long-standing practice of simply recommending preferential classroom seating can no longer be considered the standard management approach. Parents, teachers, and physicians need to be well informed of affected children's psychological status and progress. It is important to provide psychological support to school-aged subjects with UHL and advice to parents regarding their child's psychological status. In addition, early detection of the child's problems, clear delineation of psychological problems, and appropriate support can prevent frustration and secondary emotional reactions [28]. Moreover, a multidisciplinary approach for the initial assessment and active therapeutic interventions are needed in the outpatient clinic. Of course, one cannot overemphasize the importance of monitoring the good ear [39].

Although this is the first study to investigate the relationships between UHL and psychological problems in a large sample of subjects, this study has some limitations. First, the subjects analyzed in the current study are not representative of all subjects with UHL in the community. Only 19-year-old males were included in this study because the data were sourced from military conscription examinations. In other studies, it has been reported that depressive tendencies tended to decrease with age, and that being male was associated with lower anxiety and depression scores [40,41]. Second, the KMPI has not been widely documented or analyzed in the literature because its purpose is for a unique environment-that is, Korean military conscription. However, the KMPI has been officially approved for use by the Korean government and is highly similar to the MMPI as a tool for psychological evaluation, to the point that it even uses the same scoring system $[25,42]$. In addition, when interpreting KMPI results, the between-group differences in each subscale cannot be considered clinically significant. Therefore, the results of the current study should not be interpreted as a hasty generalization; instead, they should be considered as reflecting the possibility that UHL may have psychopathological effects.

In conclusion, 19-year-old males with UHL tended to have more abnormal results on personality testing than controls with normal hearing, suggesting that UHL may be related to a higher risk of psychopathology. It is hoped that the findings of this study will prompt our colleague otolaryngologists and audiologists to pay more attention to this population, and we suggest that clinicians should evaluate the psychopathological aspects of patients with UHL.

\section{CONFLICT OF INTEREST}

No potential conflict of interest relevant to this article was reported.

\section{ORCID}

$\begin{array}{ll}\text { Jae-Jin Song } & \text { https://orcid.org/0000-0002-6631-3232 } \\ \text { Eu Jeong Ku } & \text { https://orcid.org/0000-0001-5533-4989 } \\ \text { Seoyoung Kim } & \text { https://orcid.org/0000-0001-9709-5461 } \\ \text { Euitae Kim } & \text { https://orcid.org/0000-0003-0914-2331 } \\ \text { Young-Seok Choi } & \text { https://orcid.org/0000-0001-5139-9830 } \\ \text { Hahn Jin Jung } & \text { https://orcid.org/0000-0002-6015-7048 }\end{array}$

\section{AUTHOR CONTRIBUTIONS}

Conceptualization: JJS, HJJ. Data curation: SK, EK, YSC. Formal analysis: SK, EK, YSC. Investigation: SK, EK, YSC. Methodology: 
JJS, EK, HJJ.Writing-original draft: JJS, EK, HJJ.Writing-review \& editing: JJS, EJK, HJJ.

\section{REFERENCES}

1. Watkin P, Baldwin M. The longitudinal follow up of a universal neonatal hearing screen: the implications for confirming deafness in childhood. Int J Audiol. 2012 Jul;51(7):519-28.

2. Johnson JL, White KR, Widen JE, Gravel JS, James M, Kennalley T, et al.A multicenter evaluation of how many infants with permanent hearing loss pass a two-stage otoacoustic emissions/automated auditory brainstem response newborn hearing screening protocol. Pediatrics. $2005 \mathrm{Sep} ; 116(3): 663-72$.

3. Ross DS, Visser SN, HolstrumWJ, QinT, Kenneson A. Highly variable population-based prevalence rates of unilateral hearing loss after the application of common case definitions. Ear Hear. 2010 Feb;31(1): 126-33.

4. AgrawalY, Platz EA, Niparko JK. Prevalence of hearing loss and differences by demographic characteristics among US adults: data from the National Health and Nutrition Examination Survey, 1999-2004. Arch Intern Med. 2008 Jul;168(14):1522-30.

5. Nakano A, Arimoto Y, Matsunaga T. Cochlear nerve deficiency and associated clinical features in patients with bilateral and unilateral hearing loss. Otol Neurotol. 2013 Apr;34(3):554-8.

6. Song JJ, Choi HG, Oh SH, Chang SO, Kim CS, Lee JH. Unilateral sensorineural hearing loss in children: the importance of temporal bone computed tomography and audiometric follow-up. Otol Neurotol. 2009 Aug;30(5):604-8.

7. Lieu JE. Management of children with unilateral hearing loss. Otolaryngol Clin North Am. 2015 Dec;48(6):1011-26.

8. Park E, Lee G, Jung HH, Im GJ. Analysis of inner ear anomalies in unilateral congenital aural atresia combined with microtia. Clin Exp Otorhinolaryngol. 2019 May;12(2):176-80.

9. Peckham CS, Sheridan MD. Follow-up at II years of 46 children with severe unilateral hearing loss at 7 years. Child Care Health Dev. 1976 Mar-Apr;2(2):107-11.

10. Bess FH, Tharpe AM. Unilateral hearing impairment in children. Pediatrics. 1984 Aug;74(2):206-16.

11. Fischer C, Lieu J. Unilateral hearing loss is associated with a negative effect on language scores in adolescents. Int J Pediatr Otorhinolaryngol. 2014 Oct;78(10):1611-7.

12. Lieu JE, Tye-Murray N, Karzon RK, Piccirillo JF. Unilateral hearing loss is associated with worse speech-language scores in children. Pediatrics. 2010 Jun;125(6):e1348-55.

13. Niedzielski A, Humeniuk E, Błaziak P, Gwizda G. Intellectual efficiency of children with unilateral hearing loss. Int J Pediatr Otorhinolaryngol. 2006 Sep;70(9):1529-32.

14. Schmithorst VJ, Plante E, Holland S. Unilateral deafness in children affects development of multi-modal modulation and default mode networks. Front Hum Neurosci. 2014 Mar 25;8:164.

15. Newman CW, Jacobson GP, Hug GA, Sandridge SA. Perceived hearing handicap of patients with unilateral or mild hearing loss. Ann Otol Rhinol Laryngol. 1997 Mar;106(3):210-4.

16. Borton SA, Mauze E, Lieu JE. Quality of life in children with unilateral hearing loss: a pilot study. Am J Audiol. 2010 Jun;19(1):61-72.

17. Moeller MP. Current state of knowledge: psychosocial development in children with hearing impairment. Ear Hear. 2007 Dec;28(6): 729-39.

18. Fellinger J, Holzinger D, Beitel C, Laucht M, Goldberg DP.The impact of language skills on mental health in teenagers with hearing impairments. Acta Psychiatr Scand. 2009 Aug;120(2):153-9.

19. Kim T, Kim JJ, Kim MY, Kim SK, Roh S, Seo JS. A U-shaped associa- tion between body mass index and psychological distress on the multiphasic personality inventory: retrospective cross-sectional analysis of 19-year-old men in Korea. J Korean Med Sci. 2015 Jun;30(6): 793-801.

20. Kim TW, Oh CH, Shim YS, Yoon SH, Park HC, Park CO. Psychopathological influence of lumbar disc herniation in male adolescent. Yonsei Med J. 2013 Jul;54(4):813-8.

21. Lim HK, Yoon SH, Oh CH, Choo SH, Kim TH.The impact of primary spontaneous pneumothorax on multiphasic personal inventory test results in young South Korean males. Yonsei Med J. 2012 Sep; 53(5):901-5.

22. Oh CH, Park H, Kim E, Hyun DK, Chung J. Influence of Moyamoya disease on psychopathological abnormality in young males in Korea: analysis of multiphasic personal inventory test. Neurol Sci. 2013 Jun; 34(6):949-53.

23. Oh CH, Shim YS, Yoon SH, Park HC, Park CO, Lee MS. The psychopathological influence of adolescent idiopathic scoliosis in Korean male: an analysis of multiphasic personal inventory test results. J Korean Neurosurg Soc. 2013 Jan;53(1):13-8.

24. Oh CH, Lim HK, Chung J,Yoon SH, Park HC, Park CO. The psychopathological influence of congenital heart disease in Korean male adolescents: an analysis of multiphasic personal inventory test results. Yonsei Med J. 2012 Nov;53(6):1107-12.

25. Kim SH, Hur J, Jang JY, Park HS, Hong CH, Son SJ, et al. Psychological distress in young adult males with atopic dermatitis: a cross-sectional study. Medicine (Baltimore). 2015 Jun;94(23):e949.

26. Bess FH, Dodd-Murphy J, Parker RA. Children with minimal sensorineural hearing loss: prevalence, educational performance, and functional status. Ear Hear. 1998 Oct;19(5):339-54.

27. Zeitler DM, Snapp HA, Telischi FF, Angeli SI. Bone-anchored implantation for single-sided deafness in patients with less than profound hearing loss. Otolaryngol Head Neck Surg. 2012 Jul;147(1):105-11.

28. Updike CD. Comparison of FM auditory trainers, CROS aids, and personal amplification in unilaterally hearing impaired children. $\mathrm{J}$ Am Acad Audiol. 1994 May;5(3):204-9.

29. Kenworthy OT, KleeT,Tharpe AM. Speech recognition ability of children with unilateral sensorineural hearing loss as a function of amplification, speech stimuli and listening condition. Ear Hear. 1990 Aug;11(4):264-70.

30. Aghsoleimani M, Jalilvand H, Mahdavi ME, Nazeri AR, Kamali M. The acceptable noise level benefit from directionality for listeners with severe hearing loss. Clin Exp Otorhinolaryngol. 2018 Sep;11(3): 166-73.

31. Huh G, BaeYJ, Woo HJ, Park JH, Koo JW, Song JJ.Vestibulocochlear symptoms caused by vertebrobasilar dolichoectasia. Clin Exp Otorhinolaryngol. 2020 May;13(2):123-32.

32. Fellinger J, Holzinger D, Sattel H, Laucht M, Goldberg D. Correlates of mental health disorders among children with hearing impairments. Dev Med Child Neurol. 2009Aug;51(8):635-41.

33. Theunissen SC, Rieffe C, Kouwenberg M, Soede W, Briaire JJ, Frijns $\mathrm{JH}$. Depression in hearing-impaired children. Int J Pediatr Otorhinolaryngol. 2011 Oct;75(10):1313-7.

34. Bovo R, Martini A, Agnoletto M, Beghi A, Carmignoto D, Milani M, et al.Auditory and academic performance of children with unilateral hearing loss. Scand Audiol Suppl. 1988;30:71-4.

35. Colletti V, Fiorino FG, Carner M, Rizzi R. Investigation of the longterm effects of unilateral hearing loss in adults. Br J Audiol. 1988 May;22(2):113-8.

36. Lee HJ, Lee JM, Na G, Moon YM, Lee C, Jung J.Which patients with a unilateral hearing aid for symmetric sensorineural hearing loss have auditory deprivation? Clin Exp Otorhinolaryngol. 2020 Feb;13(1): 23-8.

37. Cho SD, Jang JH, Kim H, Cho YS, Kim Y, Koo JW, et al. Ear mold foreign bodies in the middle ear necessitating surgical removal: why 
otology specialists should screen candidates for hearing aids. Clin Exp Otorhinolaryngol. 2020 Aug 26 [Epub]. https://doi.org/10. 21053/ceo.2020.00850.

38. Gass CS, Burda PC, StarkeyTW, Dominguez F. MMPI interpretation of psychiatric inpatients: caution in making inferences about concentration and memory. J Clin Psychol. 1992 Jul;48(4):493-9.

39. Bess FH, KleeT, Culbertson JL. Identification, assessment, and management of children with unilateral sensorineural hearing loss. Ear
Hear. 1986 Feb;7(1):43-51.

40. Halford JB, Anderson SD. Anxiety and depression in tinnitus sufferers. J Psychosom Res. 1991;35(4-5):383-90.

41. Lee HY. Beyond hearing loss: does tinnitus cause cognitive impairment? Clin Exp Otorhinolaryngol. 2020 Feb;13(1):2-3.

42. Fiedler ER, OltmannsTF, Turkheimer E. Traits associated with personality disorders and adjustment to military life: predictive validity of self and peer reports. Mil Med. 2004 Mar;169(3):207-11. 